(c) 2008 Elsevier Ltd All rights reserved.

\title{
Delamination behaviour of very high modulus carbon/epoxy marine composites
}

\author{
N. Baral ${ }^{a}$, P. Davies ${ }^{\text {b, }}{ }^{*}$, C. Baley ${ }^{c}$ and B. Bigourdan ${ }^{b}$ \\ ${ }^{a}$ Trimaran Groupama, 56100 Lorient, France \\ ${ }^{\mathrm{b}}$ Materials and Structures Group, IFREMER Brest Centre, 29280 Plouzané, France \\ c Université de Bretagne Sud, L2PIC, BP 92116, 56321 Lorient Cedex, France \\ *: Corresponding author : P. Davies, email address : Peter.Davies@ifremer.fr, Tel. 0033298224777 \\ Fax. 0033298224535
}

\begin{abstract}
:
This paper presents a study of the delamination resistance of unidirectional carbon fibre reinforced epoxy composites manufactured from prepreg for racing yacht mast applications. Fibre modulus has been varied from 290 to $640 \mathrm{GPa}$. Two manufacturing methods, oven cure under vacuum and autoclave, were used to produce samples. Results show that delamination resistance under mode I and mixed mode loading decreases as fibre modulus increases. The manufacturing route affects $\mathrm{Gc}$ values by modifying interlaminar layer geometry but does not change the trend of lower toughness with increasing fibre modulus. For the pitch composites crack propagation is observed within the fibres, in addition to more usual matrix and interface cracking. For the very high modulus fibre composites it is no longer possible to measure the GI/IIc fracture envelope with the MMB specimen, compression failure occurs before delamination. FE analysis and instrumented specimens have been used to define the limits to the current standard test method for these materials.
\end{abstract}

Keywords: C. Delamination; A. Carbon fibres; A. Polymers; B. Fracture toughness; Mixed mode 
High performance carbon fibres can be classed in three categories, high resistance (HR), intermediate modulus (IM), high modulus (HM). The latter are often defined as those fibres with a modulus greater than $400 \mathrm{GPa}$. All these fibres are used in sports products, such as golf clubs and fishing rods, and aerospace applications. However, over the last ten years the use of HM fibres has also developed for the masts of ocean racing yachts, and particularly for 60 foot Open Class multihulls. These structures are generally in composite sandwich, carbon composite facings on honeycomb core, of length around 30 meters and weighing around $450 \mathrm{~kg}$, manufactured from prepreg either in ovens or autoclaves. Figure 1 shows a mast being laid up in a half section mould.

In order to reduce weight but maintain high stiffness architects and designers progressively increased the fibre modulus. However, a number of problems in nearly all the composite masts with fibres of modulus above $500 \mathrm{GPa}$ resulted in a limit to the fibre modulus of $450 \mathrm{GPa}$ being imposed in 2003 [1]. Compression properties are critical in these applications, and the higher modulus fibres tend to show lower compression strength [2], but delaminations have also been observed in post mortem analysis of high modulus fibre masts. The aim of the present study was therefore to examine the delamination behaviour of composites based on high and very high modulus fibres. An extensive literature exists on delamination testing of carbon fibre composites [3-5] but nearly all published test results are for HR or IM fibres. Very few publications have reported tests on the very high modulus materials. Allix et al. [6] presented a detailed study of M55J (540 GPa)/ M18 with a fiber content of $60 \%$. However, the materials studied in that work for the aerospace industry are not the same as those employed in racing yacht construction. First, the manufacturing environment in boatyards does not follow the same procedures as those for aerospace (no clean rooms, for example). The very large dimensions of mast structures also means that modular ovens rather than autoclaves tend to be employed to cure the structures, although some autoclaves are now used. The prepreg areal weights also tend to be higher in marine structures. For these reasons the few results available are not directly applicable to racing yacht structures.

The approach adopted here was first to produce two series of unidirectional carbon/epoxy panels in boatyards, using oven and autoclave manufacturing methods. Fibre modulus was varied from 290 to $640 \mathrm{GPa}$. The choice of unidirectional materials for these tests is relevant here as the majority of the reinforcement in mast structures is oriented along the main mast axis direction. The basic properties of these materials were characterized, then delamination tests were performed. First mode I behaviour was examined, using the DCB (double cantilever beam) specimen, then mixed mode results at different mode I/mode II ratios using the MMB (mixed mode bending) specimen are presented. Results are discussed in terms of manufacturing route and fibre modulus. Difficulties were encountered in measuring mixed mode delamination resistance for the highest modulus fibre specimens and finite element analyses have been used to understand why. This has enabled the limits of the applicability of the MMB test for very high modulus composites to be identified.

\section{Materials tested and quality control}

Composites reinforced with five different fibres have been tested, Table 1. All are or have been used in mast construction. The reference fibre is M46J, which is currently the most widely used fibre for this application. Figure 2 shows an example of the cross section of each fibre.

All the specimens were manufactured from 14 layers of $300 \mathrm{~g} / \mathrm{m}^{2}$ areal weight prepreg, with either Structil 367-2 or Hexcel M10 epoxy resin, from batches which had been used in mast construction.

The first series was cured in an oven at $110^{\circ} \mathrm{C}$ for 4 hours under vacuum (0.95 bar). A PTFE starter film $10 \mu \mathrm{m}$ thick was placed at mid-thickness between the 7 th and $8^{\text {th }}$ plies before cure. The second series was cured in an autoclave at $95^{\circ} \mathrm{C}$ for 6 hours with a vacuum pressure of $0.18 \mathrm{MPa}$. In this case the starter film was aluminium 20 microns thick. It should be noted that in both cases the samples were produced in boatyards specialized in the fabrication of racing yacht structures, using the same techniques as those employed for mast structures. 
Table 2 presents details of the 10 sets of material tested. The tests were designed to allow the influence of fibres, resins and fabrication method to be quantified. Standard quality control tests were performed, including glass transition temperature $\mathrm{T}_{\mathrm{g}}$ measurement by DSC, (822 Mettler Toledo DSC $10^{\circ} \mathrm{C} /$ minute heating rate), measurement of density (ASTM D3171 using weight in air and weight in water) to obtain a theoretical fibre content $V_{f}$. For the latter the nominal fibre densities in Table 1 and $a$ resin density of $1200 \mathrm{~kg} / \mathrm{m}^{3}$ were used. Short beam shear and three point flexure tests were also performed, to measure ILSS (interlaminar shear strength, ASTM 2344) and flexural modulus (ASTM 790).

Fibre contents are similar for all materials. However, the ILSS values for the two highest modulus fibre materials M55 and K637 are 20\% lower than those for the other fibres (around 46-51 compared to 62-65 MPa), independent of fabrication route. Nevertheless, even these lower values are not unusually low for this type of marine composite.

The flexural properties of all materials were determined by three point flexure on $20 \mathrm{~mm}$ wide beams at a loading rate of $2 \mathrm{~mm} / \mathrm{min}$. Different distances between supports (l) were used, to verify that a constant modulus was obtained, Figure 3. Five specimens of each material were tested. As expected the ratio $\mathrm{I} / \mathrm{h}$ needed to reach the modulus plateau, independent of transverse shear, increases beyond the standard value of 40 for the very high modulus materials. Table 3 shows the moduli values for an $\mathrm{I} / \mathrm{h}$ ratio of 60 . There is a significant $(20 \%)$ difference in the modulus values for the two pitch series. This is partly due to slightly different fibre contents, but tension tests showed a difference in modulus of only $3 \%$. The main difference comes from the fibre distributions, a resin rich region was observed on the surface of the sample with the lower modulus. The flexural modulus calculation uses the cube of measured specimen thickness but with the very large difference between fibre and resin modulus the influence of the first fibre layer position with respect to the neutral axis strongly affects the flexural modulus obtained. This difference between two nominally equivalent materials underlines the need for quality control on each batch. Microscopic examination of polished sections indicated few voids. There is a significant difference in compaction between oven and autoclave cure for all panels, as shown in Figure 4. Interply regions appear flatter in the autoclave specimens.

\section{Delamination test procedures}

\section{- Mode 1:}

The mode I tests were performed on DCB specimens according to the ISO standard 15024. Specimens were $20 \mathrm{~mm}$ wide, $4 \mathrm{~mm}$ thick, and $160 \mathrm{~mm}$ long, with a $40 \mathrm{~mm}$ long starter film, Figure 5a. Tests were performed on an Instron 4302 test frame with a $500 \mathrm{~N}$ load cell, at a crosshead loading rate of $2 \mathrm{~mm} / \mathrm{min}$. Load $(\mathrm{P})$, crosshead displacement $(\delta)$ and crack length $(\mathrm{a})$ were recorded. At least three specimens were tested for each material. The data analysis applied is that proposed by Berry [7]:

$$
C=K a^{n}(1) G_{I c}=\frac{n P \delta}{2 b a}(2)
$$

Where $G_{\mathrm{Ic}}$ is the critical strain energy release rate in $\mathrm{J} / \mathrm{m}^{2}, \mathrm{C}$ is the compliance $\delta / \mathrm{P}$ in $\mathrm{m} / \mathrm{N}, \mathrm{K}$ and $\mathrm{n}$ are empirical constants. $a$ is the crack length and $b$ is the specimen width, both in metres.

Two values can be determined, at initiation from the starter film, defined using the onset of non-linearity, and an average of values during propagation between given crack lengths. In the standard test method only the initiation values are used, as the propagation values have been shown to depend on specimen geometry [8]. However, in the present work propagation values are also presented, first because the same specimen geometry was retained throughout, but also because the mast structures of interest are largely based on UD reinforcement. The validity of this approach will be discussed further below.

\section{- Mixed mode}

The mixed mode testing (I/II) was performed using the MMB (Mixed Mode Bending) test proposed by Reeder and Crews [9,10], as described in ASTM 6671-02. Specimens were identical to those used for the mode I characterization, Figure $5 b$. Length $L$ was $60 \mathrm{~mm}$. 
Tests were performed on the same test frame, with a $10 \mathrm{kN}$ load cell, at a crosshead rate of 1 $\mathrm{mm} / \mathrm{min}$. Crosshead displacement was used in the data analysis, but machine compliance was checked by recording the loading point displacements using a digital camera and image analysis.

\section{Data analysis was performed using the expressions below:}

$$
G_{I}=3 a^{2} P^{2} \frac{(3 c-L)^{2}}{4 b h^{3} E}(3) \quad G_{I I}=9 a^{2} P^{2} \frac{(c+L)}{16 b h^{3} E}
$$

Where $\mathrm{E}$ is the flexural modulus of the specimen, given in Table 4. The mode ratio is given by:

$$
\frac{G_{I}}{G_{I I}}=\frac{4}{3}\left(\frac{3 c-L}{c+L}\right)^{2}
$$

Three mode ratios were used : $\mathrm{G}_{\mid} / \mathrm{G}_{\|}=2, \mathrm{G}_{\mid} / \mathrm{G}_{\|}=1, \mathrm{G}_{\mid} / \mathrm{G}_{\|}=1 / 4$

\section{Results}

\section{Influence of resin}

The prepreg materials tested here are based on two epoxy resins, from the two main suppliers in France for this type of application. These resins are not identical, each is a complex formulation, but their datasheet properties are similar. It was not possible to obtain unreinforced resin samples and indeed the relevance of results from tests on resins manufactured without fibres is open to discussion, so a first series of tests was run to compare their delamination behaviour on the reference M46J fibre composites. Figure 6 shows the results, and to a first approximation the results are identical for the two systems with the same (autoclave) fabrication route. Although it is not to be concluded from this that the two resin systems will confer the same properties to composites under all loadings, in the following they will be considered as equivalent in terms of delamination resistance.

Influence of fibre, mode I

Crack propagation was stable in all specimens, Figure 7 shows examples of loaddisplacement plots for all the oven cured materials.

Figure 8 shows the mode 1 results for the two series, oven and autoclave. First, it can be noted that the propagation results for each composite are quite reproducible, scatter is below $5 \%$ even though fabrication methods are not those of the aerospace industry. Mean initiation and propagation values are given in Table 4 below.

There is a significant drop in propagation values for both series as fibre modulus increases, with the highest modulus fibre composites showing very flat R-curves. The results for the M55J material are similar to those published by Allix et al. [6] who also noted a very flat R-curve compared to lower modulus fibre composites.

Fibres bridging the two crack faces are one of the causes of an increasing R-curve. This mechanism has been discussed by several authors, for example [8,11-16], and it has been noted that the effect of fibre bridging on $G_{1 p}$ values can depend on the specimen arm stiffness. This was attributed to the influence of a larger crack tip opening displacement on breaking fibres in the bridging zone in more flexible specimens. In the present case the opposite effect is noted, the stiffer samples show a smaller bridged zone and lower toughness. Nevertheless it might be concluded that the drop in delamination resistance is simply an artefact caused by the increased stiffness of the higher modulus specimens, so a M40J DCB specimen was prepared with stiffer arms by bonding unidirectional glass reinforced doublers, so the overall arm stiffness was similar to that of the M55J specimens. Figure 9 shows the test results, the propagation values are very close to those of the M40J specimens without doublers, indicating that the specimen stiffness is not responsible for the drop in delamination resistance of the high modulus fibre composites. Other possible causes will be evoked in the Discussion section below.

- Influence of fabrication procedure, mode I 
There is also a significant influence of the fabrication route on the Mode I results. For materials with the same fibres and resins the initiation values of $G_{\mathrm{Ic}}$ are similar but there is a much larger R-curve effect when they are produced in an oven, Figure 6 . An explanation for this can be found in the sections shown in Figure 4, where the interlaminar zone is far less distinct when the composites are cured in the oven. This makes fibre bridging easier as the crack plane is not flat across the specimen width [17]. This is an important observation for damage tolerance of this type of structure, though the influence of laminated geometry on other properties such as compression strength, critical in mast design, must also be considered.

- Influence of fibre on mixed mode $G_{(1,1) c}$

Five series of specimens, all produced using an oven cure, were tested under three mixed mode ratios. Table 5 presents the results, the values are initiation values, defined by non linearity of the load-displacement plot.

The overall classification of the materials remains the same, whether the tests are performed under mode I or mixed mode loading, the lower modulus fibres show higher delamination resistance. However, for the M40J samples for $50 \%$ and $75 \%$ mode II scatter is very large, these two results should be treated with caution. Figure 10 shows the mixed mode envelopes for initiation values for the M46J and M55J composites. Several criteria have been proposed to present mixed mode data [18], here the representation suggested by Benzeggagh [19] is applied.

For the pitch specimens it was not possible to perform all the tests under all mixed mode loading ratios, premature failure of the upper arm in compression was observed before crack advance. This indicates a limit to the applicability of the MMB test which will be discussed in more detail below.

\section{Discussion}

Three aspects of these results will be discussed in this section. First the fracture surface observations will be presented. Then, reasons for the lower toughness of the very high modulus composites will be proposed in terms of the morphology of the fibres. Finally, the limitations of the MMB test for these materials will be quantified.

- Fracture surface observations

All fractured specimens were observed under the optical microscope, then selected samples were broken in liquid nitrogen and coated with an Au-Pd layer and examined in more detail in a Scanning Electron Microscope (SEM Jeol JSM 6460LV). Figures 11a and 11b show high magnification photos of fracture surfaces of M46J and M55J oven cured mode I specimens. These show areas of resin fracture and fibre-matrix debonding, typical for this type of carbon/epoxy composite [20].

For the pitch composites there is a third failure mechanism which is clearly apparent, namely the propagation of cracks within fibres along the axial direction, Figures $11 \mathrm{c}$,d.

This failure mode is also observed in pitch fibre composites under mixed mode loading, $\left(G_{\mid} / G_{\|}=2\right)$, Figures $11 \mathrm{e}$ and $11 \mathrm{f}$.

The structure and properties of pitch fibres have been described previously $[21,22]$ but to the authors' knowledge the occurrence of this mode of failure in delamination tests has not been reported. Previous work has identified defects in these fibres, certain of which have missing sections, Figure 12a. The appearance of these defects (5\% of the fibers) is related to processing conditions [22]. However, the presence of the two complete halves of fibres on the two fracture surfaces here indicates that the fibre failure mechanism is not directly the result of these defects.

- The role of fibre morphology

The morphology of these fibres varies considerably. Figure 2 shows examples of scanning electron micrographs of the five fibres. These photos clearly indicate the differences in shape and dimensions. These differences will affect local stress concentrations when transverse loading is applied. Another consequence of these differences is that the amount of fibre/matrix interface will vary between materials. In order to examine this polished sections of each material were analysed, Figure $12 \mathrm{~b}$, using CAD software. At least 40 fibres of each type were analysed, the results are given in Table 6 below. Equivalent diameters are shown for the HM PAN fibres as they are not circular. 
From these values a comparison of the amount of interface $Q t_{i n t}$ in each material, the nominal area of fibres in contact with the matrix, can be made, using the expression:

$$
Q t_{\text {Int }}=p_{f} \frac{V_{f}}{S_{f}}(6)
$$

with $V_{f}$ : the composite fibre content (given in Table 2), $S_{f}$ : the fibre surface and $p_{f}$, the fibre perimeter. If we first look at how this parameter is related to delamination resistance at initiation, Figure 13 shows $\mathrm{Q}_{\mathrm{Int}}$ for each material, together with the corresponding $\mathrm{G}_{\mathrm{lc}}$ values at initiation and propagation.

These results suggest that there is at least a link between the amount of interface and $G_{1 c}$ (and hence $G_{\mid / / I c}$, as those values follow the same trend) for the PAN fibres. For these fibres increasing modulus results in more interface and lower delamination resistance. For the pitch fibres the amount of interface is much lower, the fibre diameter is larger, but the fracture energy values are still low, suggesting that it is not the interface which is critical for this material and that the fibre fracture mechanism may be the weak link. These results are interesting but must be treated with caution, the other factor which may vary is the fibre surface topology, over which we have no control in these commercial prepregs, and which has been shown to have a strong influence on delamination behaviour [23,24]. It is clear however that if cracks propagate easily within the fibre there is little to be gained by improving the fibre/matrix interface strength.

Concerning propagation values of fracture energy, there are two questions, first why are larger Rcurves measured for oven cured materials than those which have been autoclave cured, and second why do R-curves diminish for the higher modulus fibres ? The influence of the fabrication route is shown in Figure 4 and appears to be directly related to the geometry of the crack plane. Lower pressure during oven cure and different curing steps affect resin viscosity and fibre distribution. The crack plane waviness alone is not sufficient to account for the higher values, but the more tortured crack path encourages out of plane crack initiation and multiple crack formation (Figure 14).

In order to examine the influence of fibre type on results it is necessary to consider the factors which influence the development of bridged zones. Several authors have studied fibre bridging in a range of materials [11-16]. In the early work of Phillips and Wells [12] an analytical model for the influence of the tied zone indicated a decrease in intralaminar fracture energy with increasing specimen thickness, a trend equivalent to that found here with increasing fibre modulus. Sorensen and Jacobsen, testing carbon/epoxy DCB specimens of different thicknesses subjected to pure bending moments, have shown steeper R-curves as specimen thickness decreased [13] but similar propagation plateau values. However, most studies on interlaminar mode I delamination indicate an increase in propagation values of $G_{l c}$ as specimen thickness is increased [eg 11,15]. The simplest bridging models are based on the flexural behaviour of ligaments spanning the two specimen arms [14]. The ligaments deform in shear and flexure and peel away from the surface of the specimen arms. The bridging stress generated depends on the ligament properties including their stiffness, while the fracture resistance which must be overcome for the ligaments to peel off depends on the resin and interface behaviour. Recently efforts have been made to determine bridging stresses and damage parameters from standard tests [25]. Such tests allow bridging laws to be proposed, and much effort is now being directed towards the integration of these laws in numerical analyses [eg 26,27]. The present work was mainly directed at generating experimental data, a detailed analysis is required to understand the role of fibre modulus in the propagation mechanisms.

- Measurement of mixed mode delamination resistance of very high modulus fibre composites.

As indicated in Table 5 it was not possible to measure mixed mode $G_{/ / / I c}$ values for the pitch fibre composites in all cases. It appears that compression failure of the upper arm is responsible for premature failure. In order to understand this failure mode and to examine whether modification of specimen geometry might encourage crack propagation, a finite element (FE) model of the MMB specimen was constructed using the ADINA code version 8.4, Figure 15a. This is based on 2400 elements to model the composite specimen, 792 elements for the loading blocks and supports, and 14 elements for the MMB fixture.

The aim of this model, based on two-dimensional isoparametric 9-noded plane stress solid elements, is to give a description of the stress state in the specimen before crack initiation. For this reason attention has focused on the kinematic aspects of the MMB test (roller dimension, load introduction, contact equation...), and no specific crack tip refinement has been applied. More detailed models have been presented elsewhere [e.g. 28]. The number of elements has been determined with a stress convergence analysis. The material is considered using a linear elastic orthotropic model. The 
input data are shown in Table 7. Axial moduli values $\left(E_{x}\right)$, transverse moduli and shear moduli have been measured using tensile tests and 3 point bending tests with different $\mathrm{I} / \mathrm{h}$ ratios.

Simulation of tests on M46J and pitch composites indicated high strains at points A and B, Figure 15. In order to validate the model a specimen of each material was instrumented with strain gauges (figure 15b) for a mode ratio of $75 \%$ mode II, and loaded. The measured and predicted strains are shown in Table 8 below.

The maximum compressive stress is observed on the upper arm of the sample and corresponds to the point where failure is observed during tests on pitch specimens. A comparison between the calculated stress and the failure stress measured in the 3 points flexure tests (with span $=120 \mathrm{~mm}$ to correspond to a $60 \mathrm{~mm}$ crack length) shows that the maximum compressive stress is reached before crack initiation for the pitch sample whereas for the M46J sample the crack initiation occurs before the maximum compressive stress is reached. (Tables 9 and 10)

Agreement with the measured strain is quite close suggesting that the model gives a reasonable representation of the specimen response. This then allowed the influence of various parameters, including specimen thickness, initial crack length and support span, to be quantified. The results are shown in Figure 16 below, which presents required specimen thickness versus material $G_{c}$ for various values of mode ratio, in a similar way to the representation used by Carlsson \& Gillespie for the mode II ENF specimen [29]. It is clear that very thick specimens will be needed to obtain crack advance before compression failure in the pitch composites at the $G_{/} / G_{\|}$ratios corresponding to high mode II contributions. The low compression strength of the pitch composites has been noted previously and is one of the factors which have so far limited more extensive applications of these fibres. Improvements in toughness can be obtained for the M46 composites by techniques such as through-thickness pinning [30], but more work is required to quantify the reduction in in-plane properties when such techniques are used.

\section{Conclusions}

The aim of the present study was to examine the delamination behaviour of composites based on very high modulus carbon fibres in order to optimise their use in racing yacht prototypes. The results presented above show that:

Quality control testing involving ILSS and 3 points bending tests are not sufficient to evaluate the very specific behaviour of high modulus carbon fibres / epoxy laminates. In order to optimise their development specific testing procedures are required for these materials. The use of interlaminar fracture tests has shown that:

Delamination propagation resistance decreases as fibre modulus increases.

The highest modulus pitch fibres show an additional failure mechanism, axial crack propagation within the fibres, which suggests that it will be very difficult to improve the fracture toughness of composites reinforced with these fibres.

Oven manufacture results in more delamination-resistant composites than autoclave fabrication.

Finally, it is very difficult to obtain a full mixed mode fracture envelope for the pitch fibre composites with the symmetrical MMB test on account of their low compression strength. This provides a practical limitation to the applicability of mixed mode tests performed in bending. If these materials are to be employed in racing yachts development of specific damage tolerance strategies will be necessary.

\section{REFERENCES}

1. Devaux, H., Casari, P., Choqueuse, D., Davies, P., Compression behaviour and design of very high modulus fibre composite masts for racing yachts, Proceedings JNC 14, France, AMAC (2005).

2. Montagnier $\mathrm{O}$, Hochard $\mathrm{C}$, Compression characterization of high modulus carbon fibers, J. Comp. Mats, 2005, 39, 35-49.

3. Friedrich K (editor), Application of fracture mechanics to composite materials, 1989, Elsevier.

4. Brunner, A.J., Blackman, B.R.K., Davies, P., A status report on delamination resistance testing of polymer-matrix composites, to appear, Engineering Fracture Mechanics, 2007.

5. O'Brien TK, Martin RH, Results of ASTM round robin testing for mode I interlaminar fracture toughness testing of composite materials, NASA TM 104222, 1992.

6. Allix, O., Lévêque, D., Perret, P., Identification and forecast of delamination in composite laminates by an interlaminar model, Comp. Sc. Tech. (1998) 58 
7. Berry, J. P., Determination of surface fracture energies by the cleavage technique, J. Appl. Phys., 34(1) (1963) 62.

8. Davies P, Cantwell WJ, Moulin C, Kausch HH, A Study of Delamination Resistance of IM6/PEEK Composites, Comp. Sci. \& Tech., 36, 1989, 153-166.

9. Reeder, J.R., Crews, J.H., A mixed mode bending apparatus for delamination testing, NASA TM 100662, 1988 .

10. Reeder, J.R., Crews, J.H., Nonlinear analysis and redesign of the mixed-mode bending delamination test, NASA TM 102777, 1991.

11. Davies P, Benzeggagh ML, Interlaminar mode I Fracture testing, Chapter 3 in Application of fracture mechanics to composite materials, 1989, 81-112.

12. Phillips DC, Wells GM, The stability of transverse cracks in fibre composites, J. Mat. Sci. Letters, 1, 1982, 321-324.

13. Sorensen BF, Jacobsen TK, Large scale bridging in composites: R-curves and bridging laws, Composites Part A, 1998, 29A, 1443-1451.

14. Gregory JR, Spearing SM, A fiber bridging model for fatigue delamination in composite materials, Acta Materialia, 52, 2004, 5493-5502.

15. Russell AJ, Street KN, Factors affecting the interlaminar fracture energy of graphite/epoxy laminates, Proc ICCM4, 1982, Japan Soc. Composite Materials, 279-286.

16. Prel YJ, Davies P, Benzeggagh ML, de Charentenay FX, Mode I and Mode II delamination of thermosetting and thermoplastic composites, ASTM STP 1012, p 251 (1989).

17. Hojo, M., and Aoki, T., Thickness Effect of Double Cantilever Beam Specimen on Interlaminar Fracture Toughness of AS4/PEEK and T800/epoxy Laminates in Composite Materials: Fatigue and Fracture, Fourth Volume", ASTM STP 1156, Stinchcomb, W. W., and Ashbaugh, N. E., Eds., pp.281298 (1993).

18. Reeder, J.R., A Bilinear Failure Criterion for Mixed-Mode Delamination, in Composite Materials: Testing and Design, Eleventh Volume, ASTM STP 1206, Camponeschi, Jr, E.T. Ed., pp.303-322 (1993).

19. Benzeggagh $M L$, Kenane $M$, Measurement of mixed mode delamination fracture toughness of unidirectional glass/epoxy composites with mixed mode bending apparatus, Comp. Sci \& Tech., 56, 1996, 439-449.

20. Friedrich, K., Fractographic analysis of polymer composites, Chapter 11 in Application of fracture mechanics to composite materials, 1989, 425-487.

21. Gao, S-L., Mäder, E., Zhandarov, S. F., Carbon fibers and composites with epoxy resins: Topography, fractography and interphases, Carbon 42, 3 (2004) pages 515-529.

22. Yoon, S-H., Takano, N., Korai, Y., Moshida, I., Crack formation in mesophase pitch-based carbon fibres, Part 1 and 2, J. Mat. Sci. (1997) 32 ,2753-2769.

23. Drzal, L.T., Madhukar, M., Fibre-matrix adhesion and its relationship to composite mechanical properties, J. Mat. Sci. (1993) 28 569-610.

24. Park, S. J., Seo, M. K., Lee, J. R., Roles of interfaces between carbon fibers and epoxy matrix on interlaminar fracture toughness of composites, Composites interfaces 13, 2-3 (2006) 249-267.

25. Brunner AJ, Blackman BRK, Williams JG, Calculating a damage parameter and bridging stress from $G_{I C}$ delamination tests on fibre composites, Comp. Sci. \& Tech. 66, 2006, 785-795

26. Jacobsen TK, Sorensen BF, Mode I intralaminar crack growth in composites - modelling of $R$ curves from measured bridging laws, Composites A, 32, 2001, 1-11.

27. Sun $\mathrm{CT}$, Jin $\mathrm{ZH}$, Modeling of composite fracture using cohesive zone and bridging models, Comp. Sci \& Tech, 66, 2006, 1297-1302.

28. de Morais $A B$, Pereira $A B$, Mixed mode I+II interlaminar fracture of glass/epoxy multidirectional laminate- Part 1 : Analysis, Comp. Sci \& Tech., 66, 2006, 1889-1895.

29. Carlsson LA, Gillespie JW Jr, Mode II Interlaminar fracture of composites, Chapter 4 in Application of fracture mechanics to composite materials, 1989, 113-157.

30. Cartié DDR, Baral N, Baley C, Davies P, 3D reinforcement of laminates by z-pinning, JEC Composites, 12 2004, 40-42. 


\section{Figures}

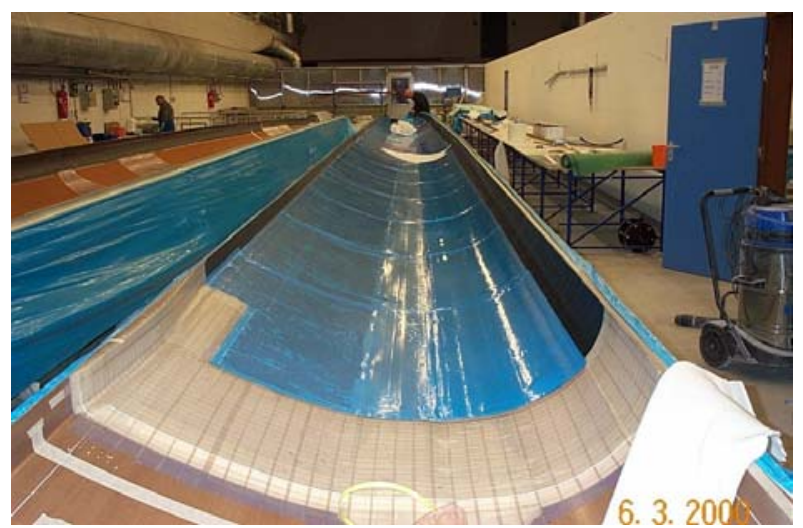

Figure 1. Mast lay-up before cure, the mast is produced in two half sections bonded together.
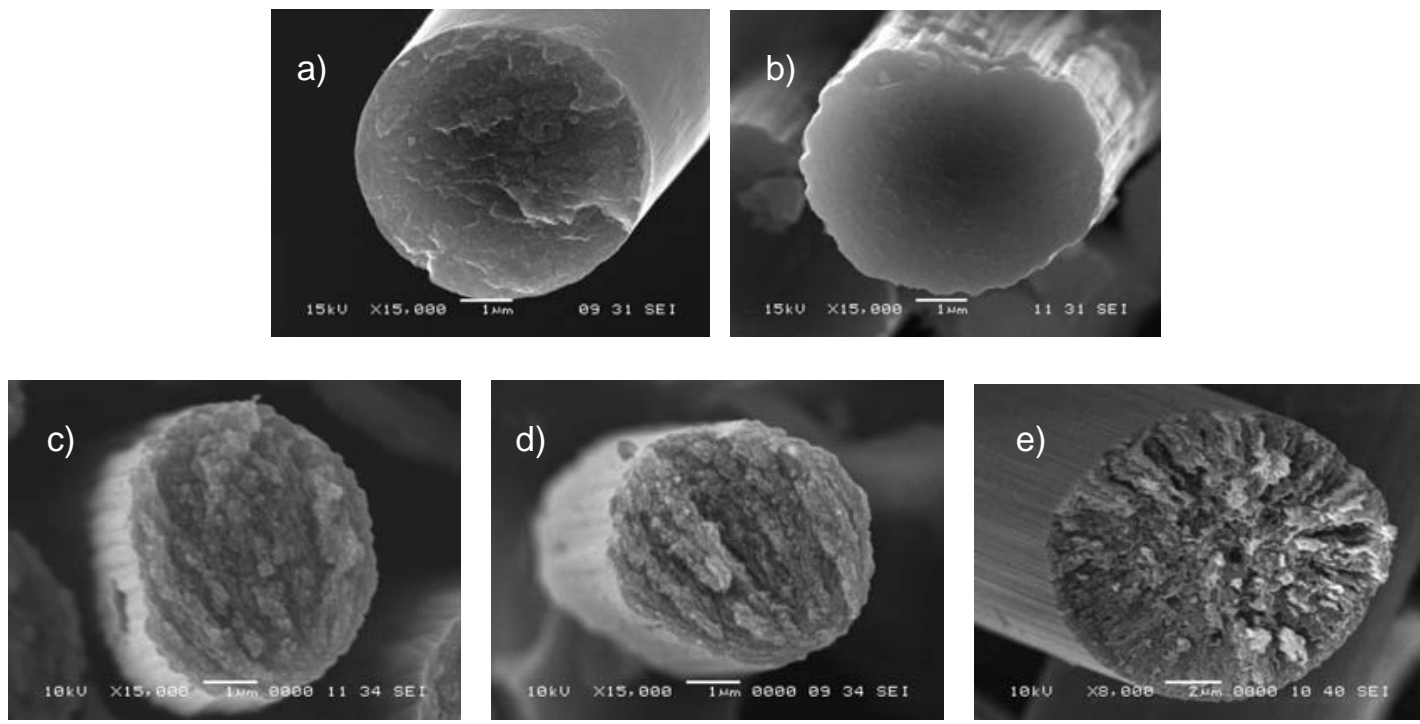

Figure 2: a).M30S,b) M40J,c) M46J,d) M55J,e) K63712 Fibre cross-sections. 


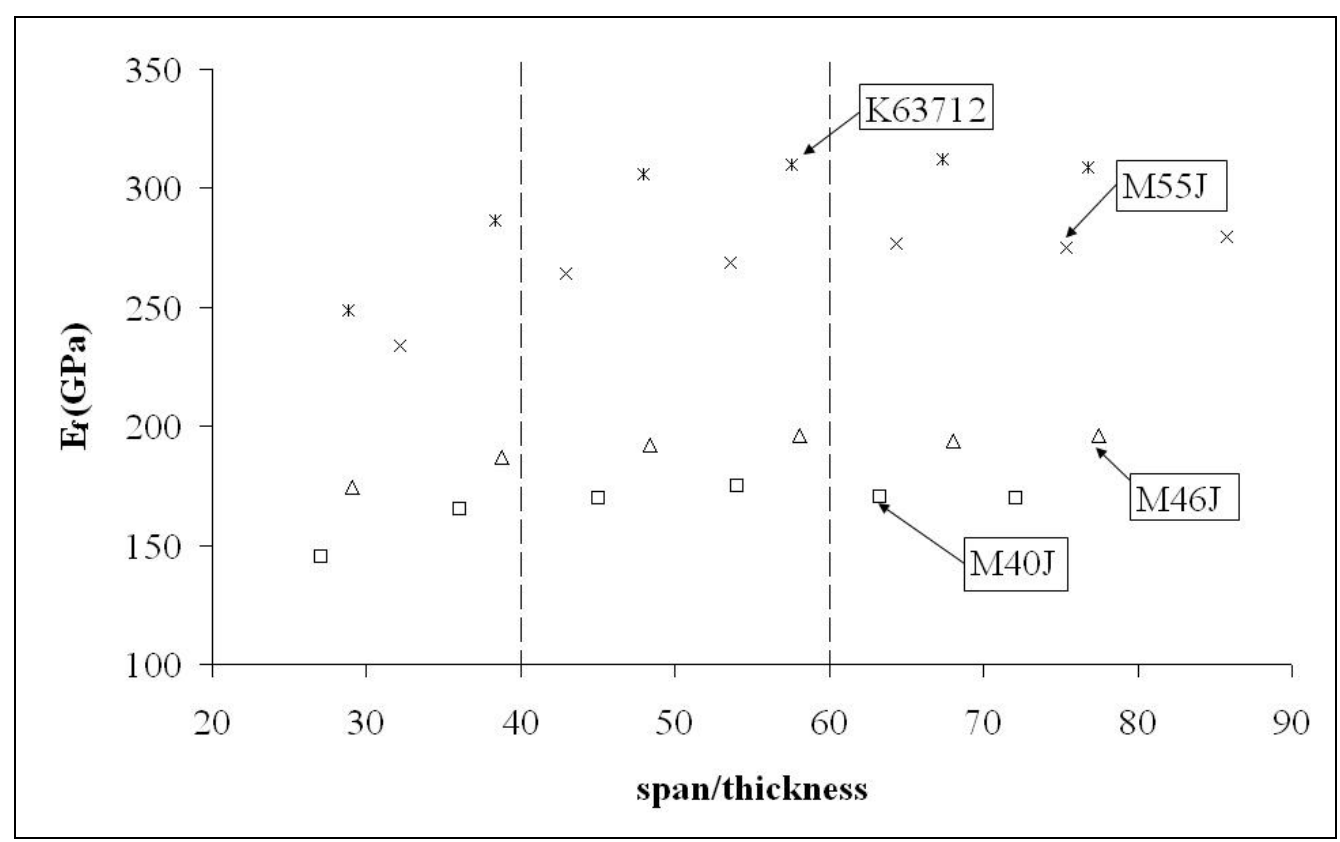

Figure 3. Influence of span to thickness ratio on measured flexural modulus.

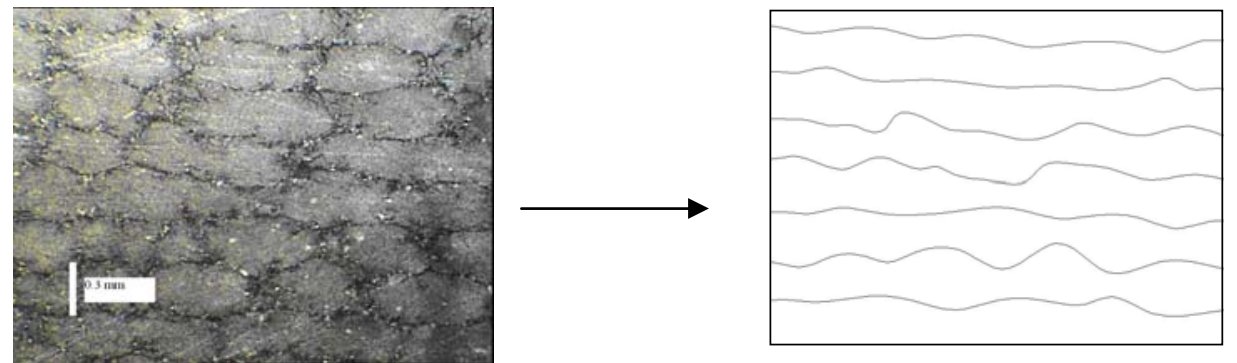

Figure 4a: microstructure of a M46J oven sample

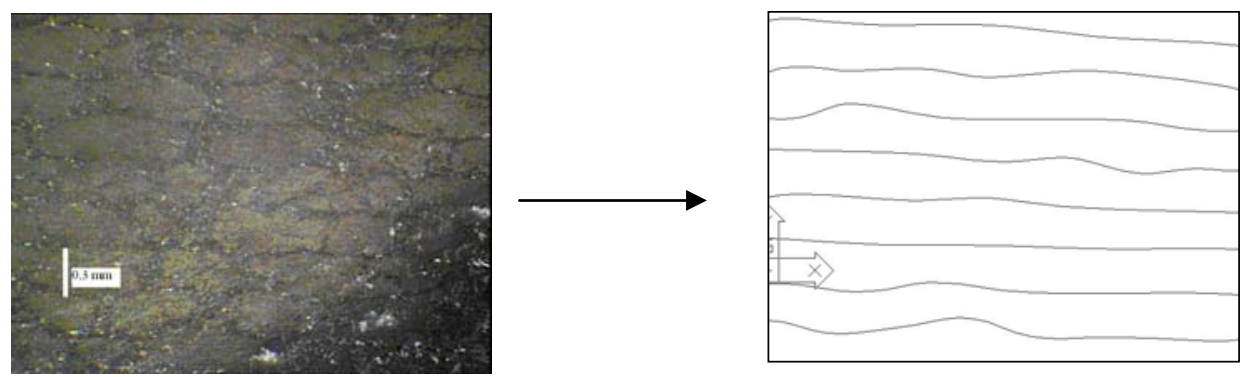

Figure 4b: microstructure of a M46J autoclave sample 


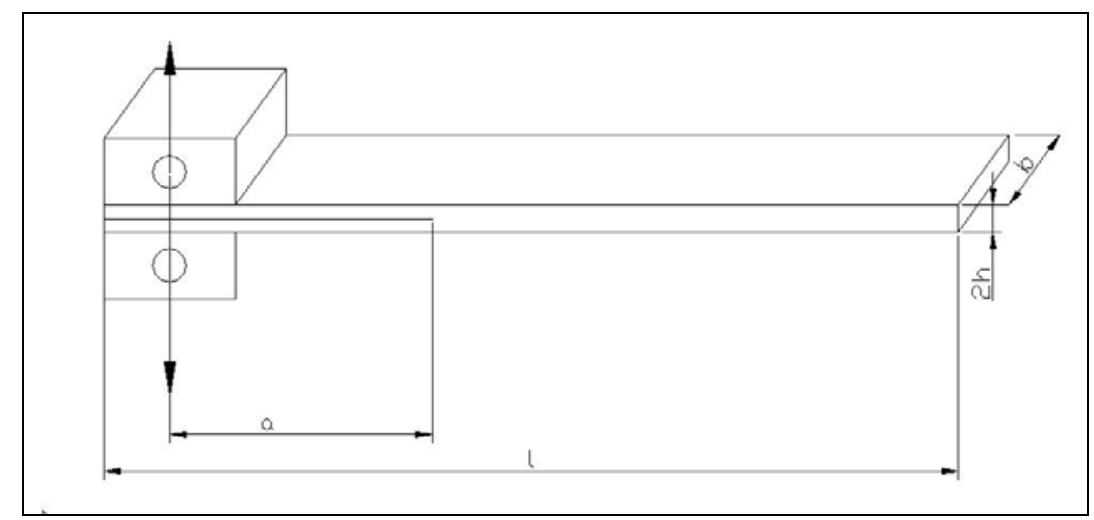

Figure 5a: DCB sample geometry

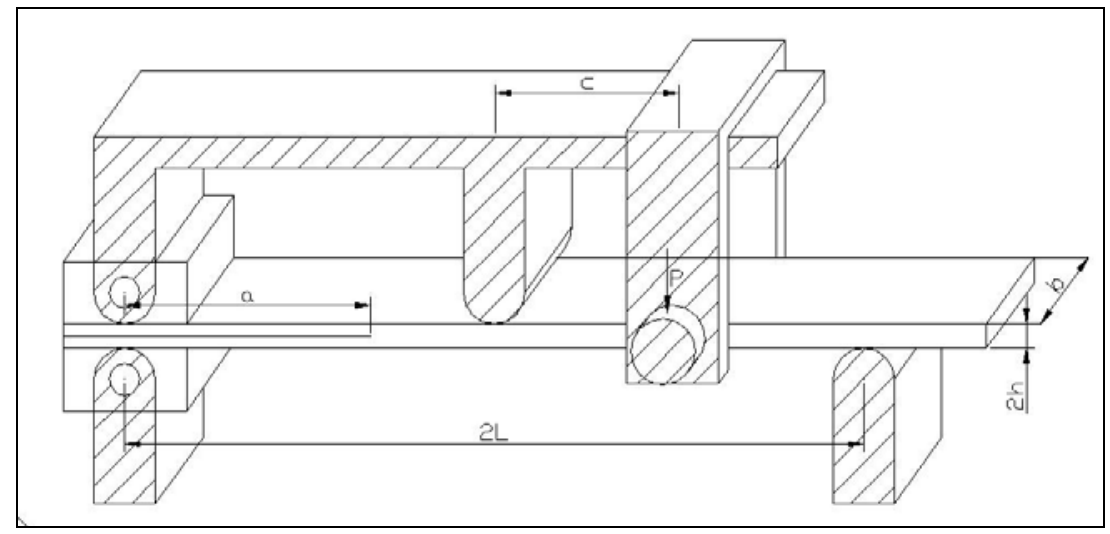

Figure 5b: MMB sample geometry and loading fixture 


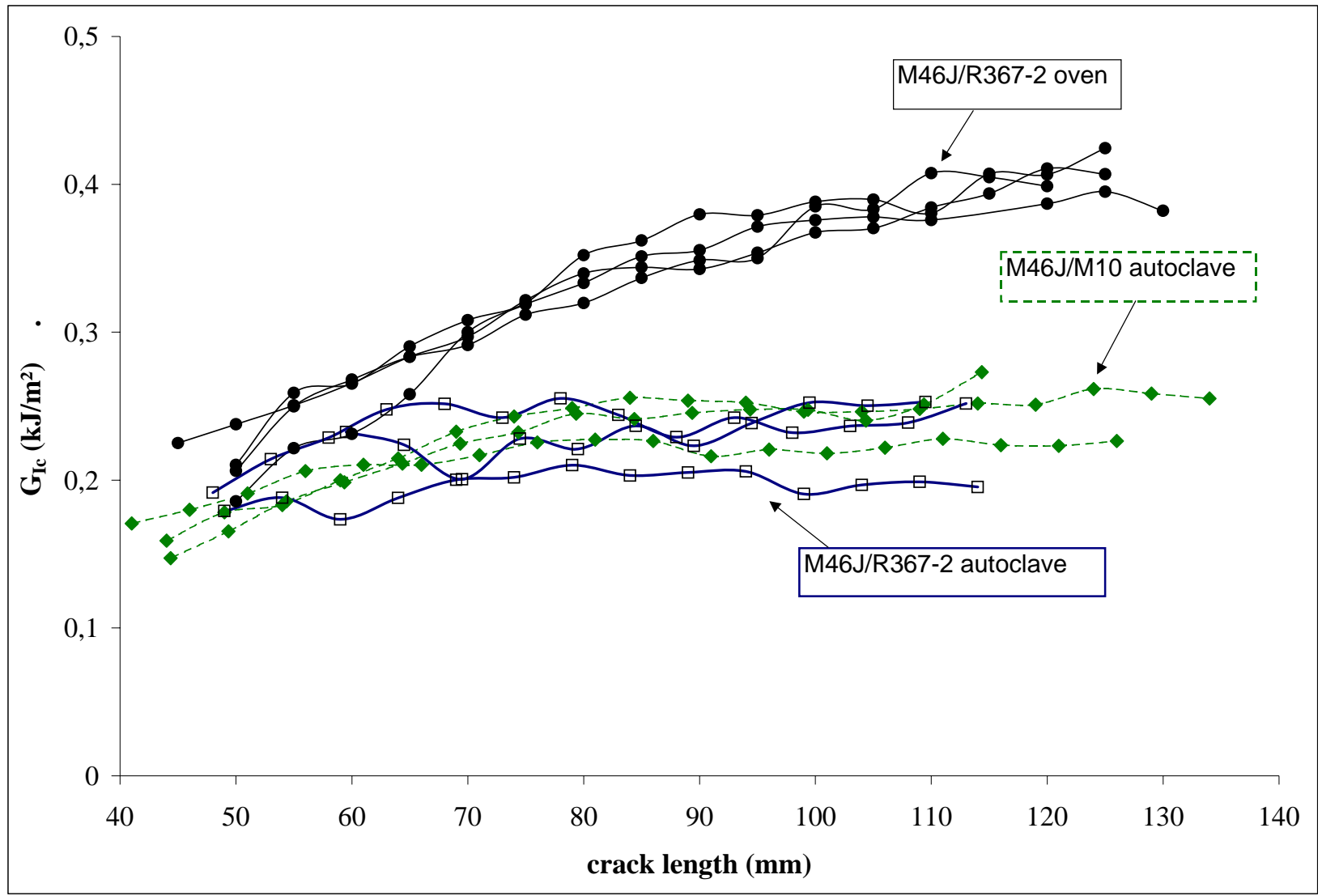

Figure 6 : Influence of fabrication route and matrix resin, M46 fibre composites.

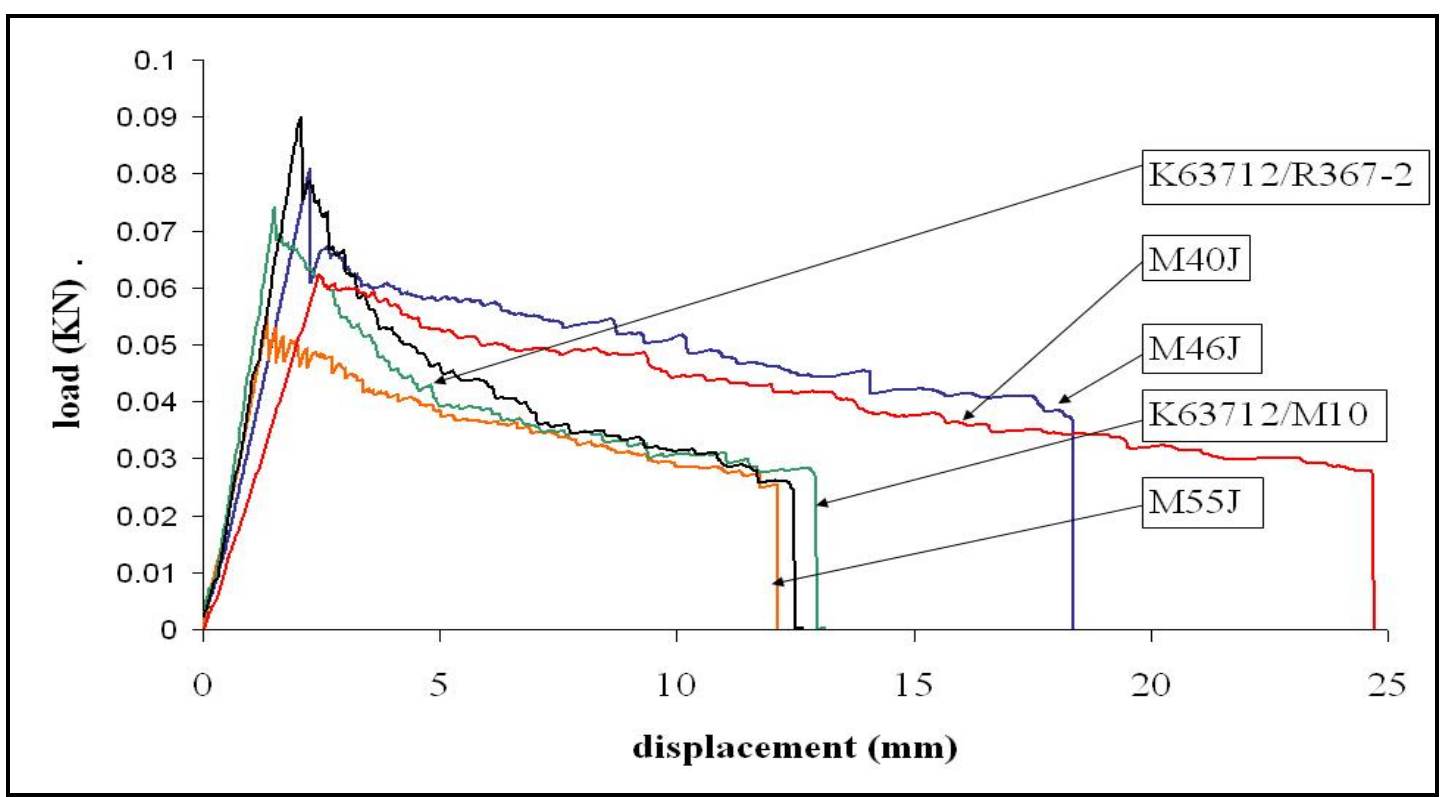

Figure 7:. Load-displacement plot examples 


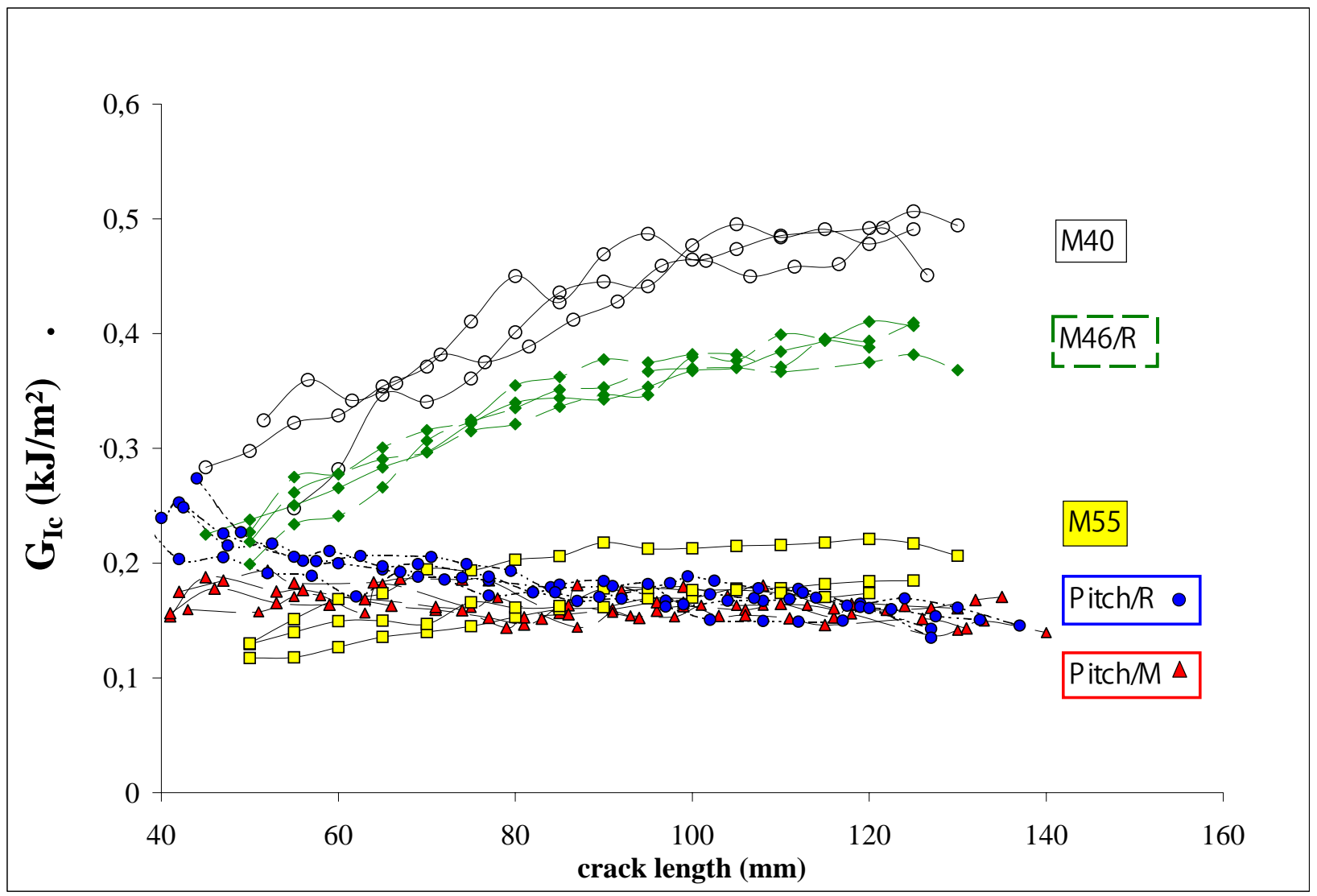

Figure 8a: Mode I results, oven samples 


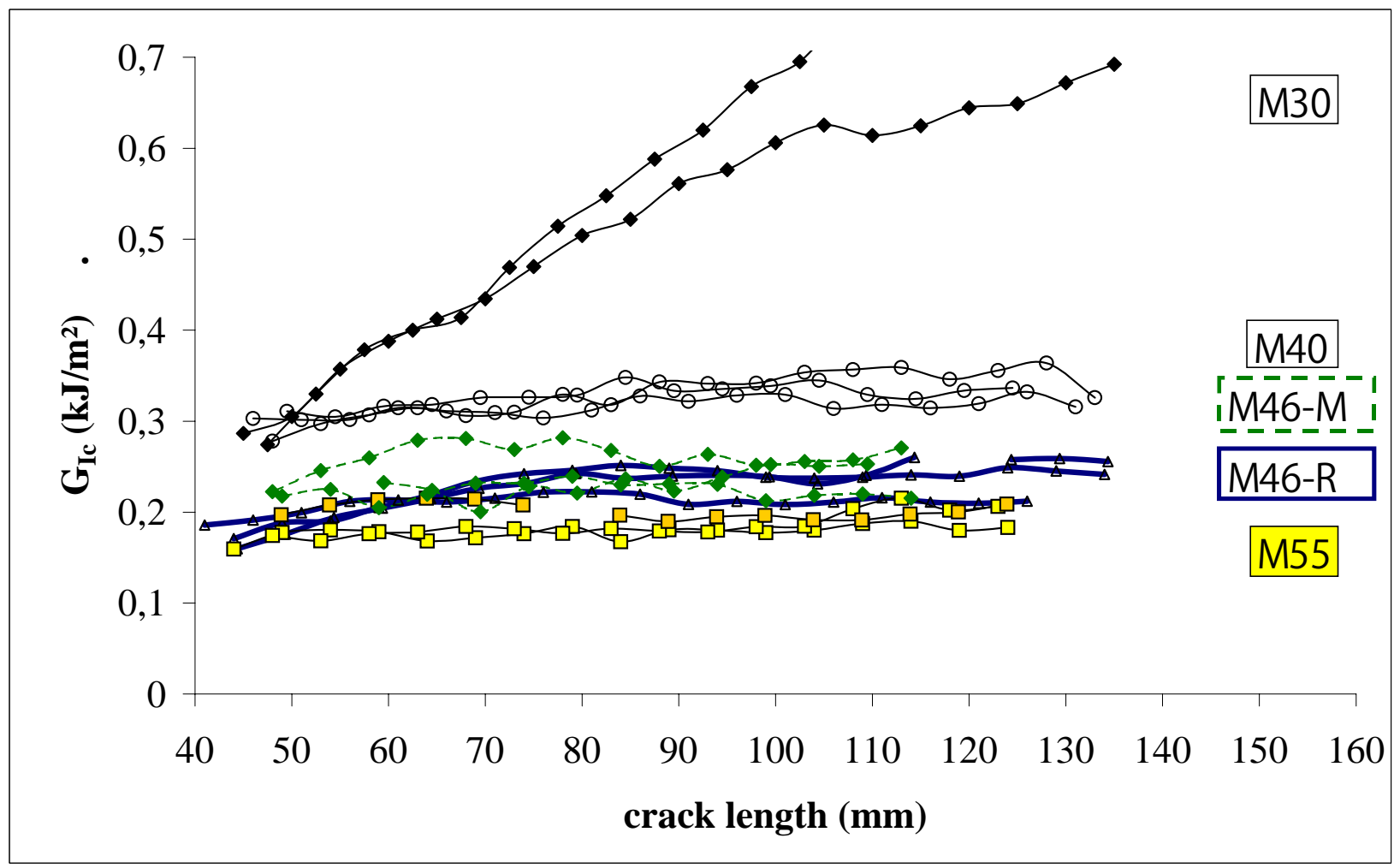

Figure 8b: Mode I results, autoclave samples

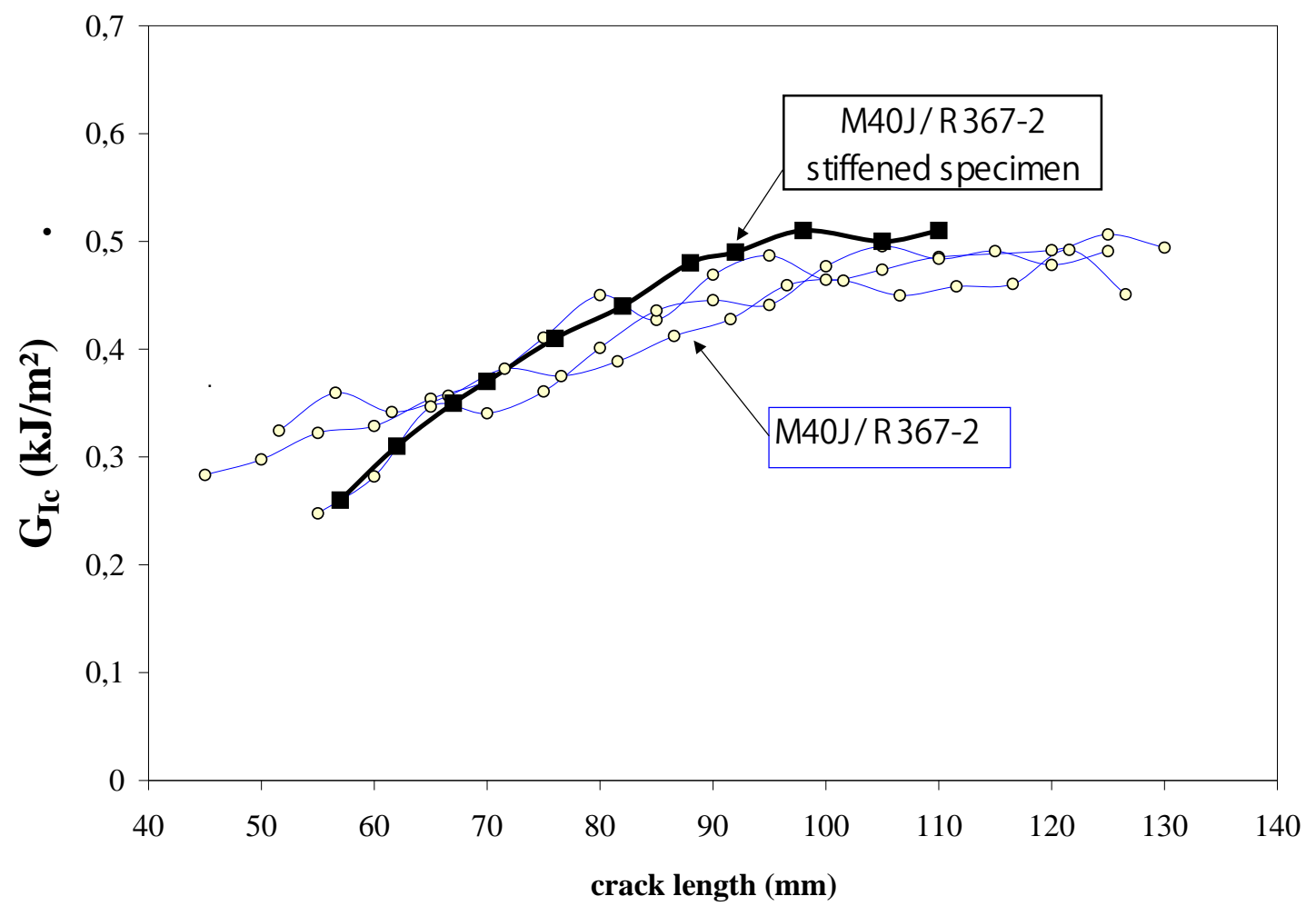

Figure $9: G_{l c}$ of a M40J stiffened sample compared to unstiffened values (initiation values unstable when stiffened) 


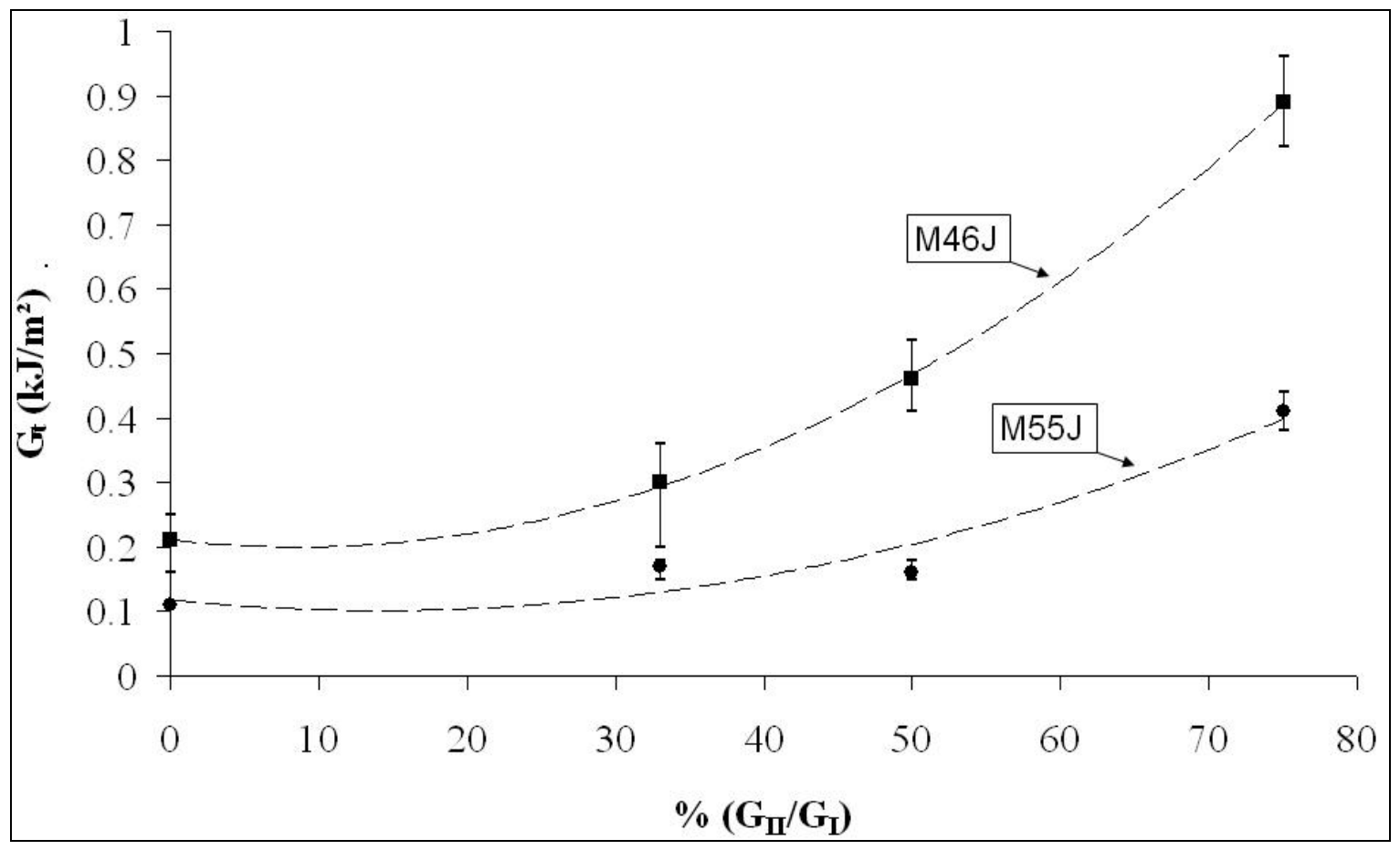

Figure 10. Mixed mode fracture envelopes for initiation
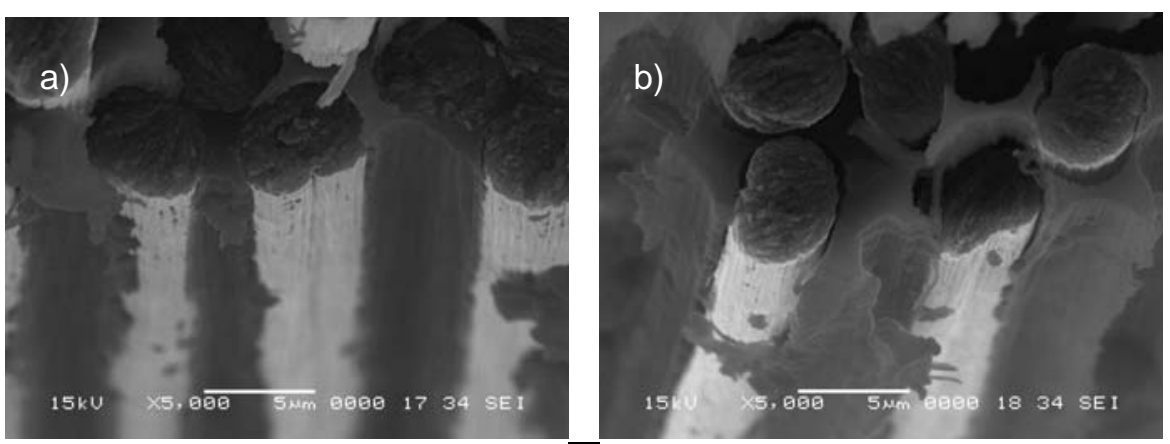

Figure 11a: fracture surface a) M46J/R367-2 b) M55J/M10 oven cure (mode 1)
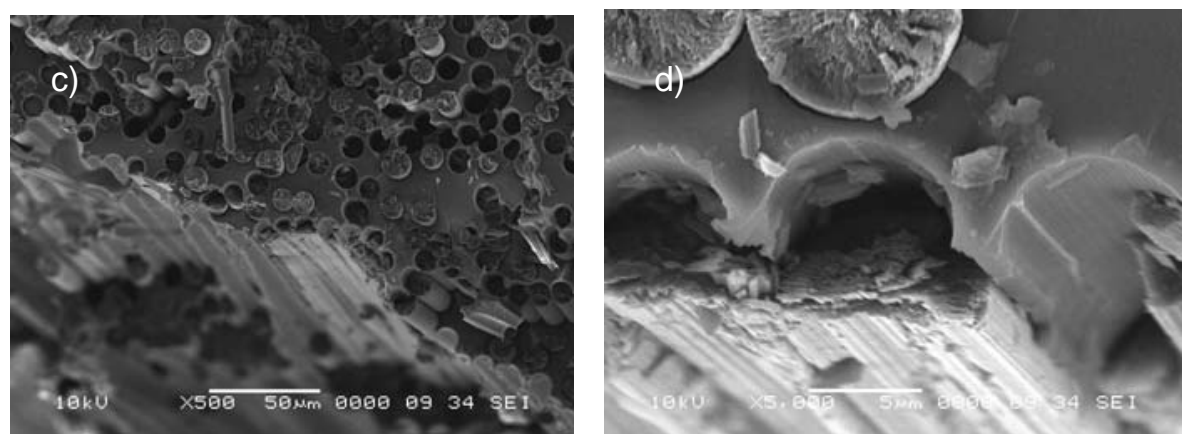

Figure 11c and 11d: fibre failure K637/M10 (mode 1), oven cure 

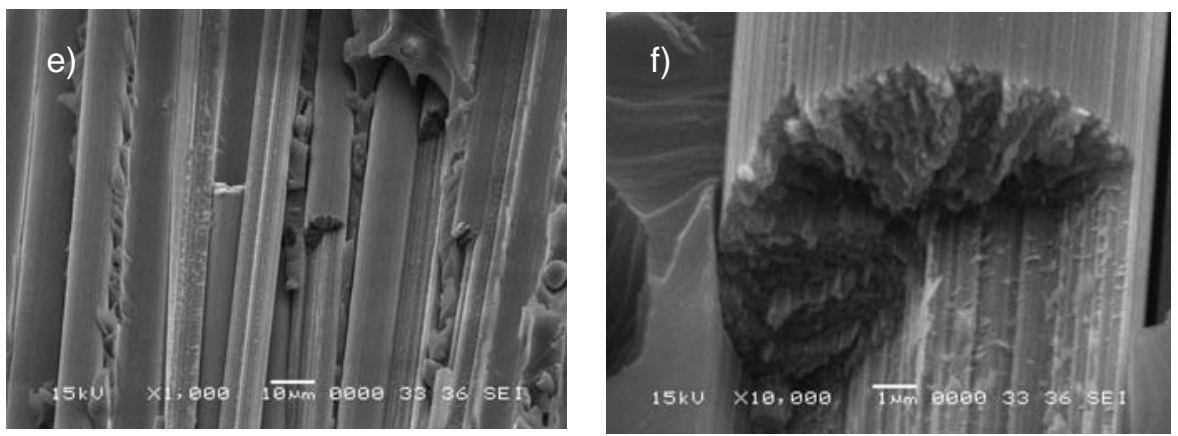

propagation

Figure 11e and 11f: fracture surface $\mathrm{K} 637 / \mathrm{M} 10$ (mixed mode $\mathrm{G}_{\mid} / \mathrm{G}_{\|}=2$ ), oven cure
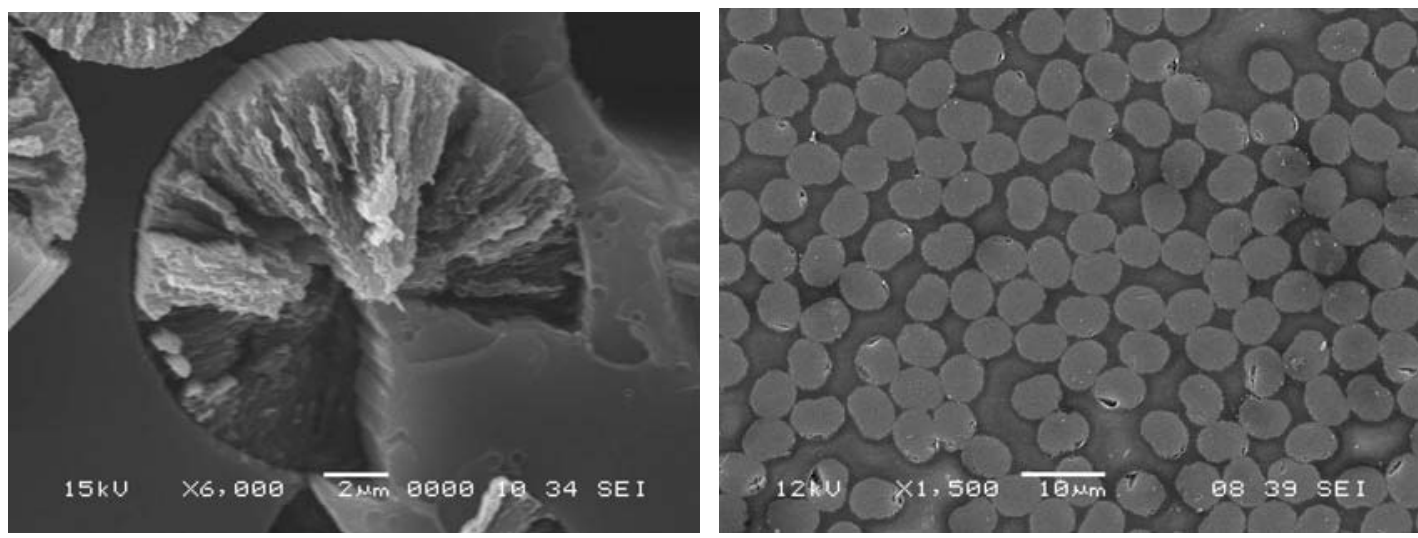

Figure 12. Fibre shapes.

a) "Pacman" defect in pitch fibre, b) transverse section M55J composite

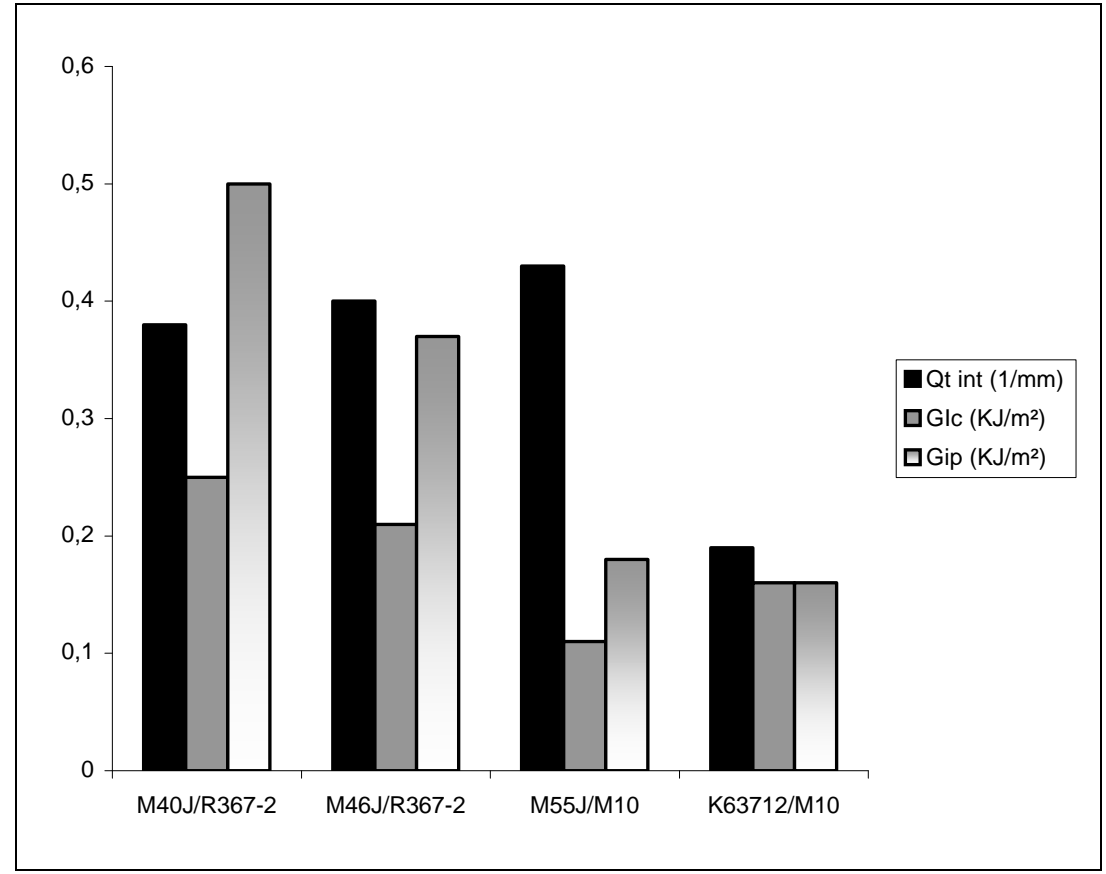

Figure 13: Interface area and $\mathrm{G}_{\mathrm{lc}}$ at initiation and propagation 

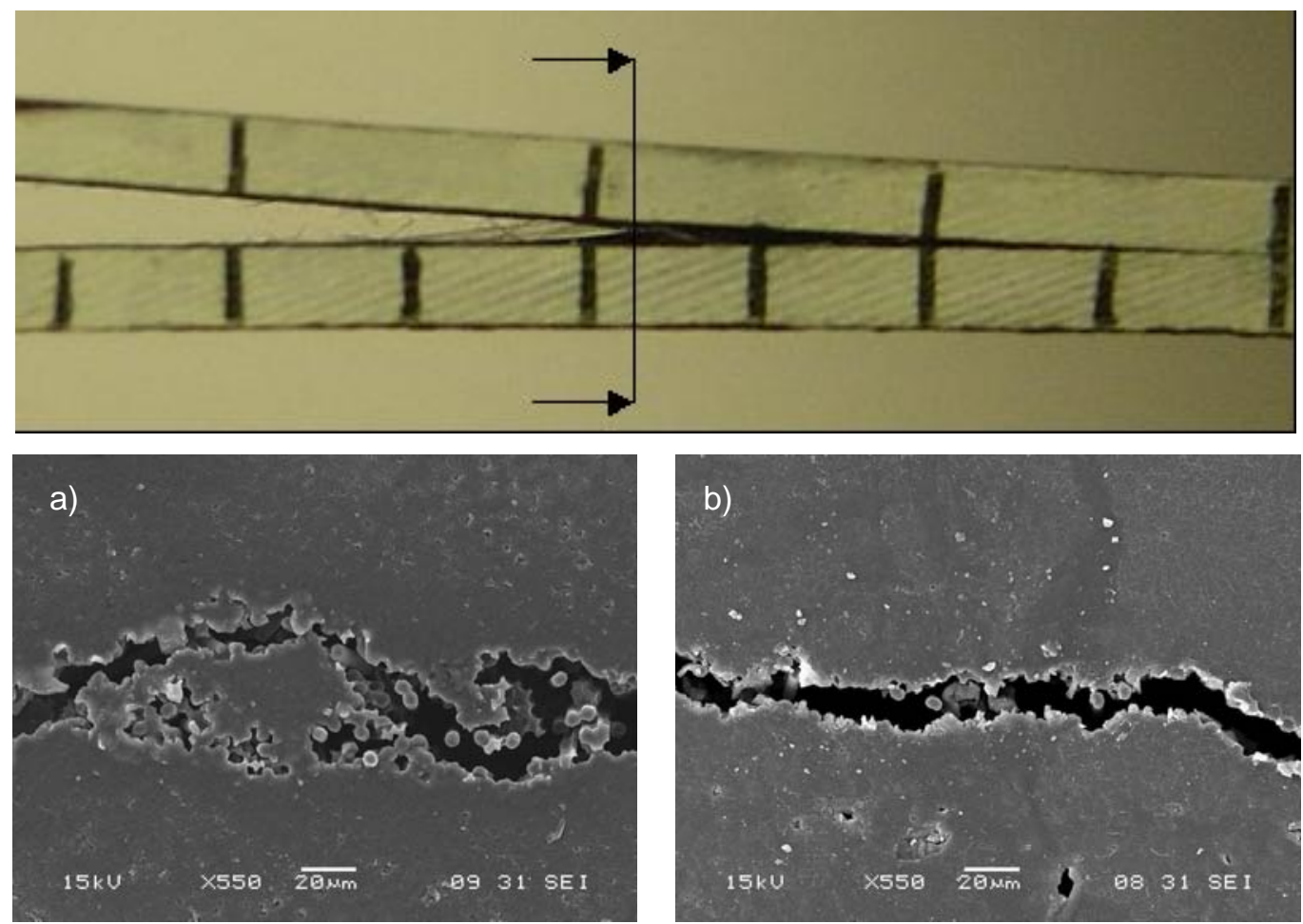

Figure 14: Sections through DCB specimens in bridging zone, showing multiple crack formation in a) M46J oven sample compared to b) M46J autoclave sample
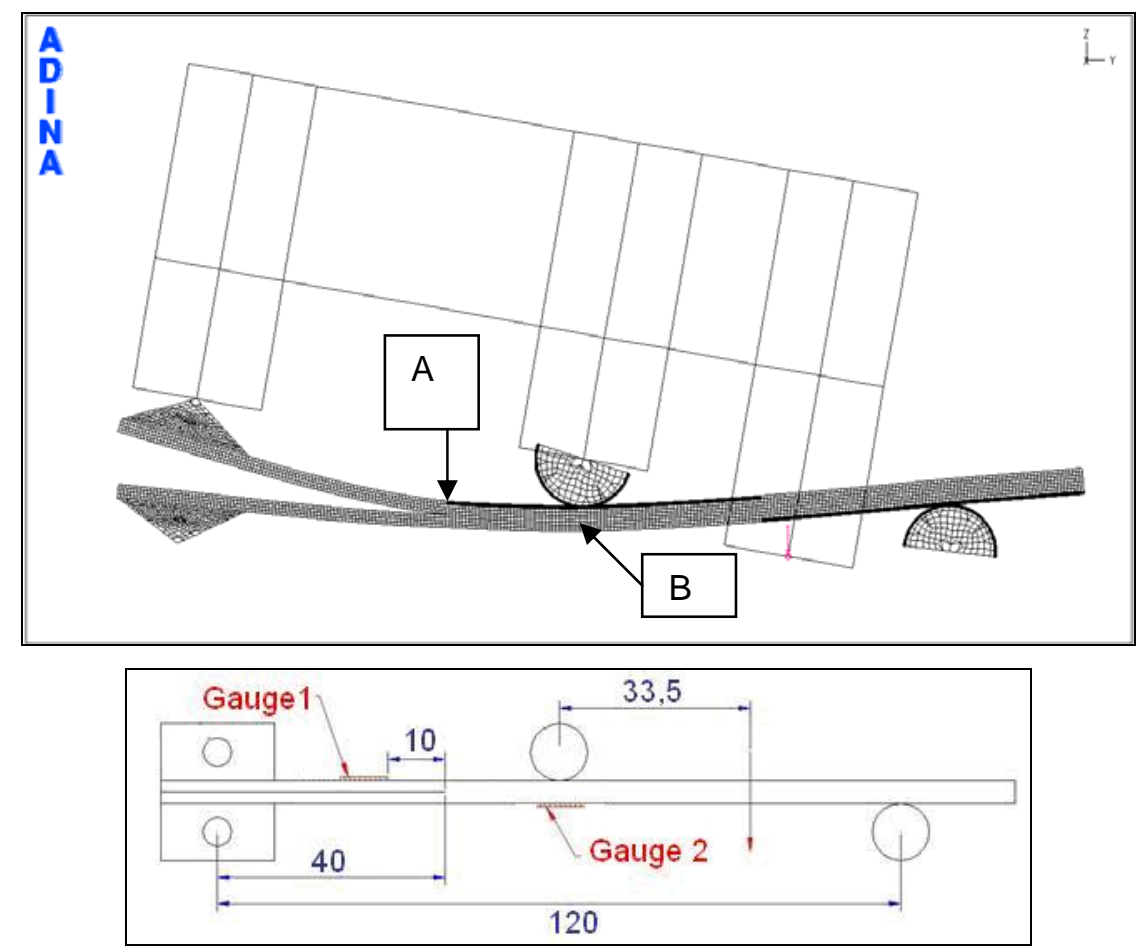

Figure 15. MMB specimen, a) FE Model, b) strain gauge location 


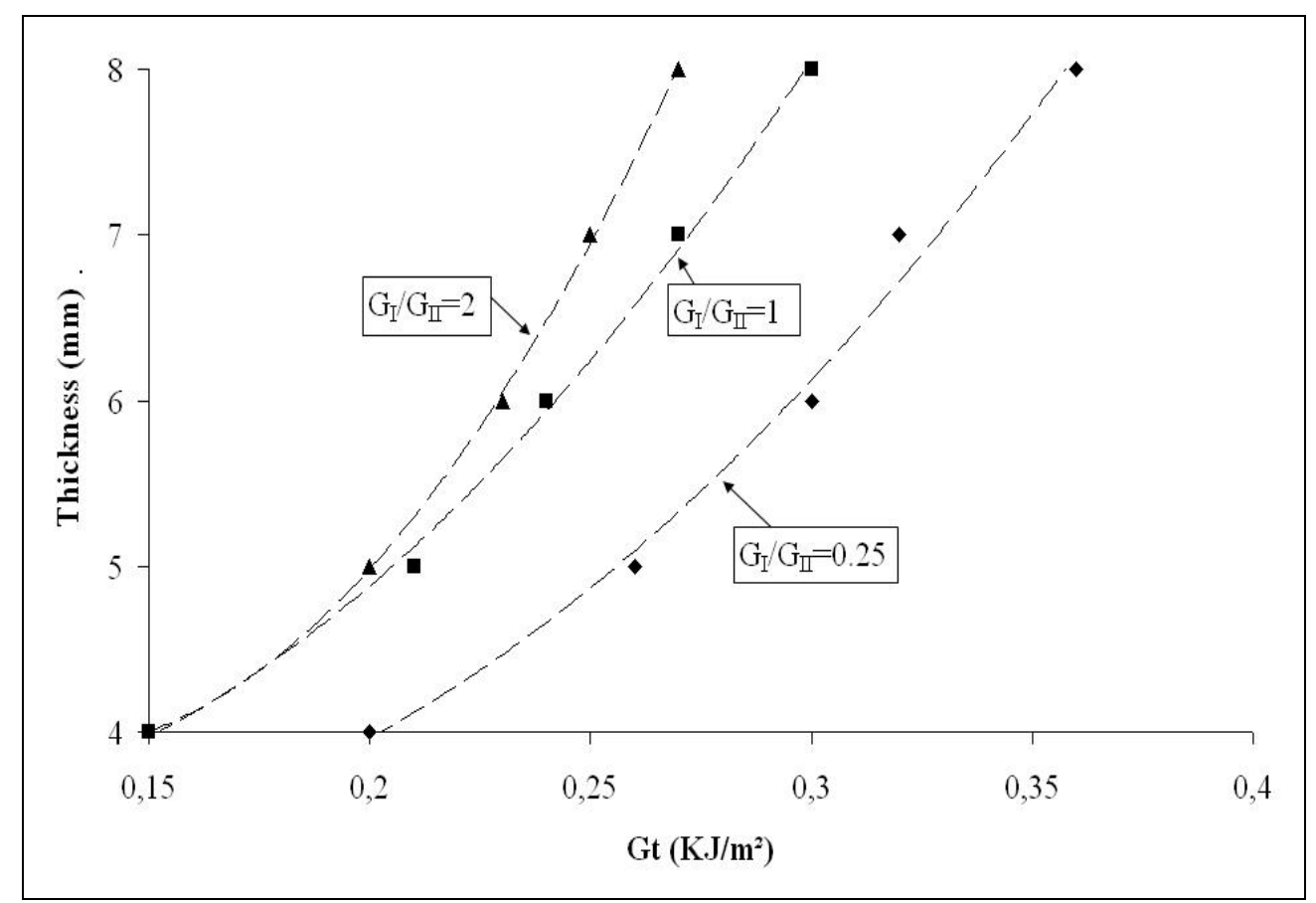

Figure 16. Specimen thickness required to avoid MMB arm failure as a function of material $G_{t}$.

\section{Tables}

\begin{tabular}{cccccc}
\hline fibre & manufacturer & type & modulus $(\mathrm{GPa})$ & $\mathrm{R}(\mathrm{MPa})$ & density \\
\hline M30S & TORAY & PAN & 294 & 5490 & 1.73 \\
M40J & TORAY & PAN & 377 & 4410 & 1.77 \\
M46J & TORAY & PAN & 436 & 4210 & 1,84 \\
M55J & TORAY & PAN & 540 & 3920 & 1.93 \\
K637-12 & MITSUBISHI & PITCH & 640 & 2600 & 2.12 \\
\hline
\end{tabular}

Table 1: selected fibres and their tensile properties [data Toray, Mitsubishi]

\begin{tabular}{cccccc}
\hline fibre & resin & density & $\mathrm{V}_{\mathrm{f}}(\%)$ & $\mathrm{Tg}\left({ }^{\circ} \mathrm{C}\right)$ & ILSS (MPa) \\
\hline \multicolumn{5}{c}{ OVEN } \\
M40J & $\mathrm{R} 367 / 2$ & 1.49 & 51 & 111 & $62(2)$ \\
M46J & $\mathrm{R} 367 / 2$ & 1.53 & 53 & 106 & $65(1)$ \\
M55J & M10 & 1.59 & 54 & 110 & $51(3)$ \\
K637 & M10 & 1.65 & 50 & 122 & $48(2)$ \\
K637 & R367/2 & 1.67 & 52 & 108 & $46(3)$ \\
\multicolumn{5}{c}{ AUTOCLAVE } \\
M30S & M10 & 1.5 & 57 & 98 & $63(2)$ \\
M40J & R367/2 & 1.5 & 53 & 100 & $64(1)$ \\
M46J & M10 & 1.55 & 56 & 110 & $63(3)$ \\
M46J & R367/2 & 1.53 & 53 & 102 & $63(6)$ \\
M55J & M10 & 1.57 & 52 & 109 & $49(2)$ \\
\hline
\end{tabular}

Table 2: Material properties, mean (standard deviation) 


\begin{tabular}{ll|lc}
\hline \multicolumn{1}{c|}{ oven } & $\mathrm{E}_{\mathrm{f}}(\mathrm{GPa})$ & \multicolumn{1}{c}{ autoclave } & $\mathrm{E}_{\mathrm{f}}(\mathrm{GPa})$ \\
\hline & & M30S / M10 & 133.5 \\
& & & $(1.9)$ \\
& & M40J / R367-2 & $(1.2)$ \\
M40J / R367-2 & $174.6(1.8)$ & & 201.9 \\
& & & $(1.5)$ \\
M46J / R367-2 & $195.3(2.4)$ & M46J / M10 & 198.2 \\
& & & $(2.1)$ \\
& & M46J / R367-2 & 275.2 \\
M55J / M10 & $269.5(6.3)$ & M55J / M10 & $(3.2)$ \\
K637 / M10 & $251.9(3.7)$ & & \\
K637 / R367-2 & $300.8(2.7)$ & & \\
\hline
\end{tabular}

Table 3. Flexural test data, mean (standard deviation)

\begin{tabular}{lcc|lcc}
\hline \multicolumn{1}{c}{ Oven } & $\mathrm{G}_{\mathrm{Ic}}\left(\mathrm{kJ} / \mathrm{m}^{2}\right)$ & $\mathrm{G}_{\mathrm{Ip}}\left(\mathrm{kJ} / \mathrm{m}^{2}\right)$ & \multicolumn{1}{c}{ Autoclave } & $\mathrm{G}_{\mathrm{Ic}}\left(\mathrm{kJ} / \mathrm{m}^{2}\right)$ & $\mathrm{G}_{\mathrm{lp}}\left(\mathrm{kJ} / \mathrm{m}^{2}\right)$ \\
\hline & & & M30S/M10 & 0.29 & 0.7 \\
M40J/R367-2 & 0.25 & 0.5 & M40J/R367-2 & 0.29 & 0.32 \\
M46J/R367-2 & 0.21 & 0.37 & M46J/M10 & 0.17 & 0.23 \\
& & & M46J/R367-2 & 0.19 & 0.24 \\
M55J/M10 & 0.11 & 0.18 & M55J/M10 & 0.16 & 0.19 \\
K637/M10 & 0.16 & 0.16 & & & \\
K637/R367-2 & $0.26^{\star}$ & 0.16 & & & \\
\hline
\end{tabular}

Table 4 Initiation and propagation (average over the crack length range from 80 to $120 \mathrm{~mm}$ ) values * unstable crack initiation.

\begin{tabular}{|c|c|c|c|c|}
\hline essai & DCB & MMB & MMB & MMB \\
\hline$\% \mathrm{G}_{\|}$ & 0 & 33 & 50 & 75 \\
\hline M40J R367-2 & $0.25(0.20-0.27)$ & $0.34(0.27-0.47)$ & $0.36(0.22-0.60)$ & $0.65(0.48-1.00)$ \\
\hline M46J R367-2 & $0.21(0.16-0.25)$ & $0.30(0.20-0.36)$ & $0.46(0.41-0.52)$ & $0.89(0.82-0.96)$ \\
\hline M55J M10 & $0.11(0.11-0.11)$ & $0.17(0.16-0.19)$ & $0.16(0.15-0.18)$ & $0.41(0.38-0.44)$ \\
\hline K637 M10 & $0.16(0.15-0.18)$ & $0.13(0.12-0.14)$ & $0.16(0.15-0.26)$ & $x$ \\
\hline K637 R367-2 & $0.26 *(0.24-0.28)$ & $x$ & $x$ & $x$ \\
\hline
\end{tabular}

Table 5. Mixed mode initiation results, $\left(\mathrm{kJ} / \mathrm{m}^{2}\right)$ oven cure, (mean and minimum/maximum values in brackets)

* unstable crack initiation. 


\begin{tabular}{lccc}
\hline & surface $\left(\mu \mathrm{m}^{2}\right)$ & perimeter $(\mu \mathrm{m})$ & equivalent diameter $(\mu \mathrm{m})$ \\
\hline M40J & $25.2(1.78)$ & $18.2(0.62)$ & 5.8 \\
M46J & $23.5(1.31)$ & $17.7(0.46)$ & 5.6 \\
M55J & $21.8(1.38)$ & $17.2(0.52)$ & 5.5 \\
K637 & $86.6(3.21)$ & $33(1.12)$ & 10.5 \\
\hline
\end{tabular}

Table 6: mean fibre measurements (standard deviation)

\begin{tabular}{ccc}
\hline material & K63712/M10 & M46J/R367-2 \\
\hline$E_{x}(G P a)$ & 302 & 225 \\
$E_{y}(G P a)$ & 5 & 6 \\
$E_{z}(G P a)$ & 5 & 6 \\
$G_{x y}(G P a)$ & 1.2 & 1.7 \\
$G_{x z}(G P a)$ & 1.2 & 1.7 \\
$G_{y z}(G P a)$ & 3 & 3 \\
$v_{x y}$ & 0.25 & 0.28 \\
\hline
\end{tabular}

Table 7: mechanical properties used for FE analysis

\begin{tabular}{ccccc}
\hline & $\begin{array}{c}\text { Applied } \\
\text { Load (N) }\end{array}$ & $\begin{array}{c}\text { crosshead } \\
\text { displacement } \\
(\mathrm{mm})\end{array}$ & $\begin{array}{c}\text { strain } \\
\text { gauge 1 } \\
\mu \text { def }\end{array}$ & $\begin{array}{c}\text { strain } \\
\text { gauge 2 } \\
\mu \text { def }\end{array}$ \\
\cline { 3 - 5 } & & 3.1 & -1880 & 1780 \\
model & & 3.14 & -1585 & 1748 \\
\hline test & 463 & 3 & &
\end{tabular}

Table 8. FE model validation, M46J sample

\begin{tabular}{ccc}
\hline sample & $\begin{array}{c}\text { FE max compressive } \\
\text { stress at crack initiation (MPa) }\end{array}$ & $\begin{array}{c}\text { Max compressive stress } \\
\text { In flexure test (MPa) }\end{array}$ \\
\hline M46J/ R367-2 & 689 & $883( \pm 23)$ \\
\hline
\end{tabular}

Table 9 :Test-model comparison for M46J sample Ratio $G_{/} / G_{\|}=1 / 4$

\begin{tabular}{ccc}
\hline & $\begin{array}{c}\text { FE max compressive } \\
\text { stress at specimen arm failure } \\
\text { sample }\end{array}$ & $\begin{array}{c}\text { Max compressive stress } \\
\text { In flexure test } \\
(\mathrm{MPa})\end{array}$ \\
\hline $\mathrm{K} 63712$ /M10 & 429 & $463( \pm 10)$ \\
\hline
\end{tabular}

Table 10: Test-model comparison for $\mathrm{K} 63712$ sample Ratio $\mathrm{G}_{\|} / \mathrm{G}_{\|}=1 / 4$ 